\title{
Efektivitas Pembelajaran Agama Kristen Melalui Mata Kuliah Pendidikan Agama Kristen di Perguruan Tinggi Terhadap Pemahaman Mahasiswa Kristen Tentang Gambar Diri
}

\author{
${ }^{* 1}$ Soleman Kawangmani, ${ }^{* 2}$ Irawan Budi Lukmono \\ ${ }^{12}$ Dosen STT Gamaliel \\ E-mail: ${ }^{* 1}$ solemankawangmani@yahoo.co.id, ${ }^{* 2}$ ibelodia@yahoo.com
}

\begin{abstract}
ABSTRAK-Status sebagai mahasiswa memiliki nilai, gengsi dan prestise tersendiri. Namun fakta berbicara bahwa pengaruh pengetahuan, filsafat dan nilai-nilai yang diterima seringkali mengaburkan gambar dirinya. Oleh karena itu mahasiswa Kristen perlu memiliki pemahaman gambar diri yang alkitabiah melalui pembelajaran Agama Kristen di kampus serta hidup sesuai dengan gambar dirinya di dalam Yesus Kristus. Penelitian ini bertujuan untuk mengetahui seberapa besar efektivitas pembelajaran Agama Kristen melalui mata kuliah Pendidikan Agama Kristen (PAK) terhadap pemahaman mahasiswa Kristen tentang gambar diri. Penelitian ini bersifat kuantitatif dengan metode Quasi eksperimen. Sampel penelitian sama dengan populasi yaitu 51 mahasiswa Kristen yang mengambil mata kuliah PAK di lingkungan Universitas Sebelas Maret Surakarta. Instrumen penelitian menggunakan Angket. Hasil penelitian uji regresi menunjukkan nilai $\mathrm{R}$ Square sebanyak 31,3\%. Hal ini menunjukkan bahwa PAK memberikan sumbangan efektif terhadap pemahaman mahasiswa Kristen tentang gambar diri sebesar $31,3 \%$.
\end{abstract}

Kata kunci: Efektivitas, Pendidikan Agama Kristen, Pemahaman, Gambar Diri

ABSTRACT-Status as a student has its own values, qualities and prestige. But the facts speak that the influence of knowledge, philosophy and accepted values often obscures his selfimage. Therefore Christian students need to have an understanding of the biblical self-image through learning Christianity on campus and living according to their own image in Jesus Christ. This study aims to determine how effective the learning of Christianity through Christian Religious Education Courses (PAK) is towards Christian students' understanding of self-image. This research is quantitative with the Quasi experimental method. The research sample is the same as the population of 51 students who take PAK Courses in the University of Sebelas Maret Surakarta. Research instruments using a questionnaire. The results of the regression test showed the value of $R$ Square was $31.3 \%$. This shows that PAK contributed effectively to the understanding of Christian students about self-image of $31.3 \%$.

Keywords: Effectiveness, Christian Religious Education, Understanding, Self-Image

\section{PENDAHULUAN}

Mahasiswa baru adalah pribadipribadi yang memiliki sejuta mimpi dan keinginan. Berbekal pembawaan yang antusias, peka dan tanggap dengan perubahan, melek teknologi, percaya diri, mudah beradaptasi dengan perkembangan zaman, serta idealisme yang kuat membawa mahasiswa pada pribadi yang memiliki standar tinggi. Harapan positif terpatri dalam pikiran mereka ketika menyandang status mahasiswa. Status 
mahasiswa, bagi mereka adalah sesuatu yang berharga dan lebih tinggi dari sekadar siswa. Sekarang sebutannya sudah berubah, dari "siswa" bertambah "maha" di depannya, yaitu "maha-siswa". Hal ini membawa kebahagiaan, gengsi, dan prestise tersendiri. Bagi mereka, gambar diri atau citra diri mereka begitu sempurna, utuh, berharga, dan bernilai.

Setelah menjalani perkuliahan dengan status mahasiswanya, realitas tentu dapat berkata lain. Antara impian dan fakta bisa berbeda. Pada semester awal, mahasiswa mengambil beberapa mata kuliah dengan konten pengajaran masingmasing. Dari berbagai mata kuliah tersebut memberi wacana, filsafat, pengetahuan, dan masukan baru bagi mahasiswa, sehingga dapat memengaruhi gambar diri. Ada pergeseran, atau bahkan pengaburan makna gambar diri. Pengaburan gambar diri ini menunjuk pada gambar diri yang salah. Ketika gambar diri salah, akan memengaruhi perkataan dan perilaku. Pemahaman terhadap identitas diri (dalam hal ini gambar diri), akan memengaruhi tindakan.

Gambar diri yang salah dapat menjadi masalah serius bagi eksistensi mahasiswa. Kasus perjudian, narkoba, miras dan seks bebas yang dipublikasikan oleh beragam media, juga sering terjadi di kalangan mahasiswa. Fakta-fakta ini menunjukan bahwa mahasiswa memerlukan pengajaran gambar diri yang benar untuk pembentukan kepribadiannya. Nicholas Kurniawan dalam tulisannya berjudul "Membangun Konsep Diri Berdasarkan Firman Tuhan" menyimpulkan bahwa langkah awalnya adalah melihat diri dari perspektif Tuhan. ${ }^{1}$ Bagi mahasiswa Kristen, pembelajaran Firman Tuhan dapat diperoleh melalui mata kuliah (makul) Pendidikan Agama Kristen (PAK). Sigit Dwi Kusrahmadi

\footnotetext{
${ }^{1}$ Nicholas Kurniawan, "Membangun Konsep Diri Berdasarkan Firman Tuhan", Veritas $1 / 2$ (Oktober 2000), 222.
}

mengatakan bahwa PAK adalah usaha membimbing peserta didik mencapai kepribadian utuh baik dalam aspek sifat, kesadaran dan tanggungjawab yang mencerminkan sebagai gambar Allah. ${ }^{2}$ Artinya dengan PAK diharapkan dapat meluruskan gambar diri mahasiswa dengan dasar Alkitab. Mahasiwa akan memiliki gambar diri yang benar dan berdampak positif terhadap kehidupannya di tengah masyarakat, bangsa dan negara.

Oleh karena sampai saat ini belum ada publikasi hasil penelitian tentang efektivitas pembelajaran agama Kristen melalui makul PAK di kampus terhadap pemahaman mahasiswa Kristen tentang gambar diri maka tulisan ini akan memaparkan tentang PAK, Gambar Diri dan hasil penelitian tentang kontribusi PAK terhadap pemahaman tentang gambar diri yang alkitabiah.

\section{RUMUSAN MASALAH}

Seberapa besar sumbangsih pembelajaran agama Kristen melalui makul PAK di Perguruan Tinggi terhadap pemahaman Mahasiswa Kristen tentang gambar diri?

Penelitian ini bertujuan untuk mengetahui seberapa efektif sumbangsih pembelajaran agama Kristen melalui makul PAK di Perguruan Tinggi terhadap pemahaman mahasiswa Kristen tentang gambar diri.

Manfaaf teoritis yaitu memperkaya khasanah bidang ilmu PAK berbasis hasil riset tentang sumbangsih strategis PAK di Perguruan Tinggi dalam rangka pembentukan kepribadian mahasiswa Kristen.

\footnotetext{
${ }^{2}$ Sigit Dwi Kusrahmadi, "Sumbangan Pendidikan Agama Kristen Dalam Mewujudkan Watak Bangsa". http://staffnew.uny.ac.id/upload/131655977/peneliti an/ Jurnal+Pendidikan+ Agama+ Kristen+1+Nov.+2007.pdf, diakses tanggal 18 Februari 2020.
} 
Manfaat praktis yaitu menyadarkan para dosen PAK di Perguruan Tinggi umum (nonteologi) tentang nilai strategis PAK dan memotivasi para dosen PAK agar lebih bersungguh-sungguh dalam persiapan dan pelaksanaan PAK.

\section{METODE PENELITIAN}

Penelitian ini menggunakan pendekatan kuantitatif dengan metode Quasi Eksperimen (Eksperimen semu). Populasi yaitu mahasiswa Kristen yang mengambil Mata Kuliah Pendidikan Agama Kristen sebanyak 51 orang. Para mahasiswa berasal dari program Pendidikan Dokter Fakultas Kedokteran UNS sebanyak 23 mahasiswa, dari Sekolah Vokasi UNS program studi D3 Mandarin 15 orang dan D3 Bahasa Inggris 3 orang, FKIP UNS program studi Pendidikan Kewarganegaraan (PKN) 4 mahasiswa, Pendidikan PAUD 1 mahasiswa dan program Kriya Tekstil (S1) Fakultas Seni Rupa dan Desain UNS sebanyak 5 mahasiswa. Besarnya sampel sama dengan jumlah populasi penelitian. Instrumen penelitian yaitu Angket kuesioner. Sample validasi instrumen sebanyak 25 mahasiswa Kristen dari Fakultas yang berbeda dengan populasi penelitian. Dilakukan uji Validitas dan Reliabilitas instrumen. Teknik analisis data yaitu Uji Hipotesis Paired Sampel T test. Uji normalitas dan Uji Homogenitas. Uji sumbangan efektivitas Unvariate R Square. Variabel $\mathrm{X}=$ Pembelajaran Agama Kristen, $\mathrm{Y}=$ Pemahaman tentang gambar diri. Indikator "Y" mancakup: (1) Gambar diri positif (asali) menurut Kejadian 1-2; (2) Gambar diri negatif setelah kejatuhan manusia dalam dosa menurut Kejadian 3-4; (3) Pemulihan gambar diri manusia di dalam Yesus; (4) Hidup dalam Yesus sebagai manusia rohani/baru. Hipotesis penelitian yaitu pembelajaran agama Kristen meningkatkan secara signifikan pemahaman tentang gambar diri.

\section{HASIL PENELITIAN DAN PEMBAHASAN}

\section{Pendidikan Agama Kristen di Perguruan Tinggi}

Pendidikan Tinggi (PT) di Indonesia tidak hanya bertujuan untuk menghasilkan alumni profesional dalam bidang ilmunya tetapi juga harus memiliki iman dan kepribadian yang berkualitas sehingga dapat berkontribusi besar dan utuh bagi kesejahteraan bangsa dan negara. Untuk mencapai tujuan ini dalam pembelajaran di Perguruan Tinggi selain makul bidang keilmuan, pemerintah juga menetapkan mata kuliah (makul) pembentukan kepribadian yaitu Pendidikan Pancasila dan Pendidikan Kewarganegaraan dan Pendidikan Agama yang wajib ditempuh oleh semua mahasiswa. $^{3}$

Bagi mahasiswa Kristen di PT Umum (nonteologi), tersedia makul Pendidikan Agama Kristen (PAK) dengan bobot 2 Satuan Kredit Semester (SKS). PAK dilaksanakan dengan visi yaitu menjadikan agama Kristen sebagai sumber nilai sekaligus pedoman dalam membentuk kepribadian kristiani yang menjunjung tinggi martabat umat manusia. Sedangkan misi PAK yaitu para mahasiswa Kristen mampu mempraktikan nilai-nilai kristiani dalam seluruh aspek kehidupannya.

PAK dengan bobot 2 SKS berarti dalam setiap minggu, setiap mahasiswa Kristen harus melaksanakan 2 jam kegiatan pembelajaran akademik dengan dosen MAKUL PAK, 2 jam kegiatan terstruktur terkait dengan PAK dan 2 jam kegiatan secara mandiri. Atau total 6 jam per minggu harus disediakan mahasiswa untuk PAK. Melalui semua aktivitas PAK, mahasiswa Kristen diharapkan mencapai

\footnotetext{
${ }^{3}$ T. Haryono, R. Ginting, Soleman Kawangmani, Yuliati, Efi Nurwindayani, Hery Harjanto, K. Jimmy Sanger, Pendidikan Agama Kristen, (Surakarta: LPPMP UNS, 2016), 1
} 
pemahaman dan pengalaman akan kasih Allah di dalam Kristus dan oleh kuasa transformatif dari Firman Allah dan bimbingan Roh Kudus dapat bertumbuh menjadii pribadi yang dewasa secara holistik sehingga mampu membuktikan dan membaktikan dirinya secara bertanggung dalam seluruh aspek kehidupan demi kemuliaan Allah dan kebaikan sesama manusia. $^{4}$

Rancangan PAK minimal sebanyak 14 kali tatap muka, satu kali UTS dan satu kali UAS. Substansi Kajian PAK yaitu Tuhan Yang Maha Esa, manusia, etika dan Moral, iman dan IPTEK, budaya, masyarakat, hukum, politik dan kerukuan antar umat beragama. PAK berpusat pada mahasiswa (student oriented) dan bukan Teacher Oriented. Metode pembelajaran sangat beragam yaitu ceramah, presentasi, diskusi kelompok, pemahaman Alkitab melalui Kelompok Tumbuh Bersama Kontekstual (KTBK) atau Contextual Bible Group (CBG), Problem Based Learning $(P B L)$, Drama dan Retreat.

Berdasarkan substansi kajian dalam PAK, maka subtansi tentang Tuhan Yang Maha Esa memperkenalkan dokrin Alkitab tentang pribadi Allah, karya-Nya dan cara pencipta mengenal Dia serta doktrin tentang pribadi Yesus Kristus dan karyaNya. Substansi kajian tentang Manusia membahas tentang penciptaan manusia, kejatuhannya dalam dosa, penebusan dan pemulihan di dalam Yesus Kristus serta implikasi etis dalam hidup sebagai orang yang beriman kepada Yesus Kristus. Kedua substansi kajian ini sangat berperan dalam menolong mahasiswa Kristen memahami tentang gambar diri alkitabiah.

\section{Tinjauan Iman Kristen Tentang Gambar Diri}

Pengertian Gambar Diri
Gambar diri (self image) adalah bagaimana seseorang melihat dirinya. ${ }^{5} \mathrm{Hal}$ ini menyangkut pemahaman tentang siapa, bagaimana, dan harus menjadi apa dirinya. Ada dua aspek yang berkaitan dengan gambar diri, yaitu aspek masa kini (who $i$ am now) dan aspek masa yang akan datang (who $i$ will be). Kedua aspek ini menjadi satu kesatuan yang menggerakkan seseorang menjalani kehidupannya.

Adapun faktor-faktor yang mempengaruhi gambar diri seseorang adalah: Pertama, faktor genetis yaitu latar belakang keluarga, jenis kelamin, suku, riwayat hidup, kronologi waktu dan lain sebagainya. Kedua, faktor perubahan dalam diri seseorang misalnya cacat permanen, ditinggalkan orang yang sangat dikasihinya.

\section{Gambar Diri Menurut Alkitab}

(1) Gambar Diri Positif (Asali) Menurut

Kejadian 1-2

Manusia diciptakan Allah secara langsung (Kej. 1:27; 2:7; 5:1; U1. 4:32). ${ }^{6}$ Menurut Kejadian 1:26, manusia diciptakan menurut gambar dan rupa Allah (bhs. Ibrani: tselem demuth). Tselem menunjuk pada gambar, artinya bahwa komponen-komponen yang dimiliki Allah juga dimiliki manusia (pikiran, perasaan, dan kehendak). Demuth berarti keserupaan, kemiripan. Dengan kata lain, demuth menunjuk pada kualitas. Menurut gambar dan rupa Allah dalam bahasa Latin diterjemahkan imago dan similitudo. ${ }^{7}$ Dalam perjanjian Baru disebut eikon dan homoiosis. $^{8}$

Manusia diciptakan segambar dengan Allah. Keadaan manusia pada waktu diciptakan: berarti yaitu manusia

\footnotetext{
${ }^{5}$ Erastus Sabdono, Gambar Diri, (Jakarta: Rehobot Literature, 2017), 1.

${ }^{6}$ Paul Enns, The Moody Handbook of Theology, (Chicago: Moody Press, 1989), 303.

${ }^{7}$ Charles C. Ryrie, Pengantar Teologi Dasar, Jilid 1, (Yogyakarta: Yayasan ANDI, 1993), 256.

${ }^{8}$ Ibid., 257.
} 
memiliki tujuan Ilahi (Kej. 1:28), aman, terjamin (Kej. 1:29), dan dimiliki (Kej. 2:18). ${ }^{9} \quad$ Sebagai makhluk mulia yang diciptakan menurut gambar dan rupa Allah, manusia memiliki rasa berharga, rasa aman (dimiliki), dan rasa berdaya guna. $^{10}$

Manusia adalah makhluk ciptaan Allah yang memiliki karakteristik unik dan istimewa. Ciri-ciri penciptaan manusia adalah: rencana agung Allah yang didahului dengan pertimbangan yang agung pula ${ }^{11}$, secara langsung, khusus, dan segera $^{12}$, berbeda dengan makhluk lain ${ }^{13}$. Tujuan Allah menciptakan manusia sebagai: klimaks penciptaan ${ }^{14}$, mediator Allah atas ciptaan lainnya (Kej. 1:28) yaitu diberi mandat Ilahi ${ }^{15}$ dan otoritas atas segala ciptaan-Nya ${ }^{16}$, bersekutu dan memuliakan Allah. ${ }^{17}$

Manusia memiliki warisan positif dari penciptaan yang meliputi hidup secara jasmani atau bios yang menggambarkan persatuan antara tubuh jasmani dan bagian dari diri, yaitu akal atau pikiran, emosi atau perasaan, dan kehendak. Warisan positif yang lain adalah hidup secara rohani atau zoe yaitu kehidupan yang tidak dapat membusuk, berada dalam persatuan dengan Allah. Manusia diciptakan secara

${ }^{9}$ Neil T. Anderson, Siapa Anda Sesungguhnya?, (Bandung: Lembaga Literatur Baptis, 2004), 26.

${ }^{10}$ Irawan Budi Lukmono, Pengembangan Pribadi, (Karanganyar: GSJA Air Kehidupan, 2018), 1.

${ }^{11}$ Louis Berkhof, Teologia Sistematika

Jilid 2, (Jakarta: LRII, 1994), 5.

${ }^{12}$ Charles C. Ryrie, Pengantar Teologi

Dasar, Jilid 1, (Yogyakarta: Yayasan ANDI, 1993), 256.

${ }^{13}$ Louis Berkhof, Teologia Sistematika, 7.

${ }^{14}$ Paul Enns, The Moody Handbook, 40.

${ }^{15}$ Eugene H. Merril, "A Theology of The

Pentateukh" dalam A Biblical Theology of The Old Testament, 14.

${ }^{16}$ Herbert Wolf, An Introduction to The Old Testament Pentateuch, (Chicago: Moody Press, 1991), 31.

${ }^{17}$ Paul Enns, The Moody Handbook, 40. utuh, sempurna, dan memiliki maksud kekal.

Manusia sebagai "imago dei" memiliki dimensi-dimensi. ${ }^{18}$ Pertama, sebagai makhluk rohani yaitu memiliki persekutuan yang akrab dengan Allah dan kehidupan kekal. Kedua, sebagai makhluk rasional, yaitu memiliki daya cipta kreatif. Ketiga, sebagai makhluk bermoral, yaitu bebas untuk memilih dan bertindak, namun Allah memberi hukum etis. Keempat, sebagai makhluk sosial, yaitu berelasi dengan sesamanya.

(2) Gambar Diri Negatif Setelah Kejatuhan Dalam Dosa Menurut Kejadian 3-4;

Kejadian pasal 3 mencatat bagaimana manusia memberontak perintah Allah. Manusia jatuh dalam dosa. Akibat dosa manusia membawa konsekuensi terhadap multidimensi keberadaan manusia. ${ }^{19}$ Pertama, sebagai makhluk rohani, kehilangan persekutuan dengan Allah (Kej. 3:8, 10, 22-24), kehilangan kemuliaan Allah dan kehidupan kekal (Rm. 3:23; 6:23). Kedua, sebagai makhluk rasional, pikiran manusia meleset dari kebenaran (Kej. 3:8-10). Ketiga, sebagai makhluk etis, memiliki banyak pilihan. Keempat, dosa memunculkan perasaan bersalah, takut, malu (Kej. 3:7, 10). Kelima, sebagai makhluk sosial, rusaknya hubungan (Kej. 3:12-14; 4:1-8). Akibat jatuhnya manusia dalam dosa yaitu kematian rohani. ${ }^{20}$

\section{(3) Pemulihan Gambar Diri Di Dalam} Yesus

Gambar diri seseorang akan berkaitan dengan nasib kekal (keselamatan). Karena itu, perlu pembangunan gambar diri (rebuild) dan penyusunan gambar diri (redesign) di dalam Yesus Kristus. Pemulihan gambar

\footnotetext{
${ }^{18}$ T. Haryono, Saved by Faith, (Surakarta:

Yayasan Gamaliel, 2015), 2-3.

${ }^{19}$ Ibid, 3-5.

${ }^{20}$ Neil T. Anderson, Siapa Anda, 33-35.
} 
diri berarti menemukan kembali kemuliaan Allah pada keadaan seperti rencana agung Allah. Pemulihan terjadi ketika seseorang menerima keselamatan di dalam Kristus yang menjadi Sosok teladan gambar diri yang benar (Flp. 2:4-7).

Orang percaya yang dipulihkan gambar dirinya akan menghargai diri sebagai ciptaan Tuhan yang unik, istimewa, dan sempurna. Orang percaya yang dipulihkan gambar dirinya akan berpengaruh pada buah yang dihasilkan mencerminkan Kristus yang berkarya dalam dirinya (Mat. 7:16).

Berikut adalah karya Kristus bagi manusia dalam pemulihan hidup:

a. Pembenaran

Pembenaran adalah tindakan pengadilan yang olehnya Allah menyatakan benar mereka yang percaya kepada Kristus (Rm. 8:33). ${ }^{21}$ Manusia yang bersedia percaya kepada-Nya dibenarkan karena iman (Rm. 5:1), yaitu dianggap belum pernah berbuat dosa. Manfaat pembenaran adalah kedamaian (Rm. 5:1), akses tak terbatas kepada Allah (Rm. 5:2), pengharapan kekal melalui keselamatan (Rm. 5: 3-4, 9, 11), pemulihan persekutuan yaitu hubungan yang benar dengan Allah. Sesudah dibenarkan, orang percaya dipanggil melakukan kebenaran dan menyatakan kemuliaan-Nya (Yak. 2:22; 1 Pet. 2:9). Iman yang benar akan terpancar melalui tindakan yang sesuai dengan karakter Kristus. Orang percaya akan menerima upah sesuai dengan perbuatan dengan motivasi yang benar (1 Kor. 3:11-15).

b. Penebusan

Penebusan dicapai Allah ketika Ia mengutus Anak-Nya ke dunia untuk mengangkat dan membebaskan manusia dari perbudakan dosa. ${ }^{22}$ Harga penebusan yaitu dengan penumpahan darah Kristus (Ibr. 9:22). Yesus mempersembahkan

\footnotetext{
${ }^{21}$ Tony Evans, Sungguh-sungguh Diselamatkan, (Batam: Gospel Press, 2005), 29.

${ }^{22}$ Ibid., 43-45.
}

Hidup-Nya sebagai pembayaran atas dosa (Ibr. 9:11-14). Tentu pembayaran ini tidak diberikan kepada Iblis. Hasil dari penebusan adalah: manusia dibebaskan dari kutukan (Gal. 4:4-5), manusia menjadi keluarga-Nya dan memiliki hak istimewa.

c. Pendamaian

Kematian Kristus merupakan pembayaran lengkap untuk dosa manusia, dan Allah puas sepenuhnya. Allah menyediakan korban pendamaian-Nya sendiri.

Allah Bapa mengutus Yesus sebagai korban pendamaian bagi manusia. Didamaikan artinya memuaskan sepenuhnya kemarahan Bapa karena ketidakadilan. Allah tidak lagi marah dan menghukum manusia karena korban pendamaian Kristus (1 Yoh. 4:9-10). Allah mengampuni dan melupakan dosa, serta pelanggaran manusia (Mzm. 103:6-14). Dalam pendamaian, dua sifat Allah: kasih dan adil bertemu (Mzr. 85:11).

d. Rekonsiliasi

Rekonsiliasi berhubungan dengan dihilangkannya permusuhan dan pemulihan keharmonisan suatu hubungan. Tembok yang memisahkan telah dibongkar, keretakan hubungan dipulihkan melalui kematian Yesus Kristus. ${ }^{23}$

Jurang pemisah antara manusia dan Allah telah dijembatani oleh salib. Rekonsiliasi dengan Allah mempengaruhi rekonsiliasi manusia dengan sesamanya. Orang percaya memiliki tugas sebagai penyambung lidah Allah, memulihkan dan melakukan rekonsiliasi dengan sesama.

e. Lahir Baru

Lahir baru merupakan kebangkitan rohani. Dahulu mati, sekarang hidup di dalam Kristus. Itu berarti terjadi kebangkitan (Rm. 6:4-5, 13). Lahir baru adalah menjadi ciptaan baru di dalam Kristus (2 Kor. 5:17; (Yoh. 3). Ketika manusia lahir baru, ia akan memperoleh 
kehidupan kekal. Hidup kekal yang diberikan Yesus adalah kehidupan yang berkualitas (Yoh. 17:3).

\section{f. Kasih Karunia}

Kasih karunia adalah penyediaan tak habis-habisnya akan kebaikan Allah dan dengannya Ia dapat berbuat untuk manusia yang tidak pernah dapat melakukan untuk dirinya sendiri. Kasih karunia berhubungan dengan karya Allah, yang olehnya Ia dapat menembus sejarah dan memecahkan persoalan yang manusia tidak dapat pecahkan. Kasih karunia adalah pemberian Allah (Ef. 2:8). ${ }^{24}$ Langkahlangkah menerima kasih karunia adalah ${ }^{25}$ : pertama, menyadari bahwa dirinya seorang yang berdosa yang lanyak dihukum dan dimurkai Allah (Rm. 3:23; 6:23). Kedua, menyadari bahwa usaha sendiri adalah siasia. Ketiga, menyadari bahwa Yesus adalah satu-satunya Juruselamat. Keempat, menerima Yesus sebagai Juruselamat.

\section{g. Pengudusan}

Pengudusan adalah kebenaran yang berisi ganda dan meliputi ditempatkan tersendiri dari sesuatu dan ditempatkan tersendiri untuk sesuatu yang lain. Allah menempatkan orang percaya tersendiri untuk Diri-Nya sendiri segera setelah Kristus menebus. ${ }^{26}$ Kristus menguduskan orang percaya agar semakin hari semakin serupa dengan-Nya. Pengudusan berarti orang percaya diberi kedudukan mulia oleh Kristus dan kehidupan seturut dengan kebenaran-Nya.

(4) Hidup dalam Yesus sebagai manusia rohani/baru.

Manusia yang lahir baru di dalam Kristus akan memiliki identitas yaitu: garam dan terang dunia (Mat. 5:13-14), anak-anak Allah (Yoh. 1:12; Rm. 8:14; 1 Yoh. 3:1-2), sahabat Allah (Yoh. 15:15;

\footnotetext{
${ }^{24}$ Ibid., 110.

${ }^{25}$ T. Haryono, Saved by Faith., 22-23.

${ }^{26}$ Tony Evans, Sungguh-sungguh, 128-129.
}

Gal. 3:26, 28), ranting yang menghasilkan buah (Yoh. 15:1-2, 16), hamba kebenaran (Rm. 6:18, 22), ahli waris Allah (Rm. $8: 17)$, bejana tanah liat yang memiliki Allah (2 Kor. 4:7), bait Allah (1 Kor. 6:19), anggota tubuh Kristus (1 Kor. 12:27), ciptaan baru (2 Kor. 5:17), orang benar dan kudus (Ef. 1:1; 4:24), buatan Allah (Ef. 2:10), keluarga Allah (Ef. 2:19), gambaran kehidupan-Nya (Kol. 3:4; Ibr. 3:14), anak terang (1 Tes. 5:5), batu hidup (1 Pet. 2:5), bangsa yang terpilih (1 Pet. 2:9-10), perantau (1 Pet. 2:11), musuh Iblis (1 Pet. 5:8), lahir dari Allah (1 Pet. 5:18).

Ketika seseorang menjadi manusia baru, maka dirinya dibenarkan (Rm. 5:1; 2 Kor. 5:21), mati terhadap dosa, bebas dari hukuman (Rm. 8:1), menerima Roh Allah (1 Kor. 2:12), menerima pikiran Kristus (1 Kor. 2:16), milik Allah (1 Kor. 6:19-20), dimeteraikan (2 Kor. 1:21; Ef. 1:13-14), hidup untuk Allah (2 Kor. 5:14-15), dikaruniakan berkat rohani (Ef. 1:3), dipilih (Ef. 1:4-5), ditebus (Ef. 1:6-8), beroleh jalan ke sorga (Ef. 2:18), dapat menghampiri Allah (Ef. 3:12), dilepaskan (Kol. 1:13), dipenuhi dalam Kristus (Kol. 2:7), dibangkitkan bersama Kristus (Kol. $2: 12-13 ; 3: 1-4)$, roh yang membangkitkan kasih (2 Tim. 1:7), diselamatkan (2 Tim. 1:9, Tit. 3:5), dikuduskan (Ibr. 2:11), menerima janji (2 Pet. 1:4).

Berdasarkan tinjauan teoritis di atas, maka pembelajaran Agama Kristen melalui Mata Kuliah PAK di Perguruan Tinggi Umum sebagai Mata Kuliah pengembangan kepribadian akan efektif meningkatkan pemahaman para mahasiswa Kristen tentang gambar dirinya di dalam Yesus Kristus.

\section{Data Penelitian}

Uji prasyarat dalam penelitian ini meliputi uji Normalitas, uji Homogenitas, uji Hipotesis. Kemudian dilakukan uji 
Paired Samples Test

\begin{tabular}{|c|c|c|c|c|c|c|c|c|}
\hline & \multicolumn{5}{|c|}{ Paired Differences } & \multirow{3}{*}{$\mathrm{T}$} & \multirow{3}{*}{ Df } & \multirow{3}{*}{$\begin{array}{l}\text { Sig. (2- } \\
\text { tailed) }\end{array}$} \\
\hline & \multirow[t]{2}{*}{ Mean } & \multirow[t]{2}{*}{$\begin{array}{c}\text { Std. } \\
\text { Deviation }\end{array}$} & \multirow[t]{2}{*}{$\begin{array}{l}\text { Std. } \\
\text { Error } \\
\text { Mean }\end{array}$} & \multicolumn{2}{|c|}{$\begin{array}{l}95 \% \text { Confidence } \\
\text { Interval of the } \\
\text { Difference }\end{array}$} & & & \\
\hline & & & & Lower & Upper & & & \\
\hline $\begin{array}{r}\text { Pair } 1 \text { PRETEST - } \\
\text { POSTTEST }\end{array}$ & -1.961 & 2.683 & .376 & -2.715 & -1.206 & $\begin{array}{r}5.21 \\
9\end{array}$ & 50 & .000 \\
\hline
\end{tabular}

Tabel 1.Tabel Paired Test

Sumbangan Efektivitas. Hasil pengujian sebagai berikut:

a. Uji normalitas.

Uji normalitas data menggunakan rumus kolmogorov smirnov. Dasar pengambilan keputusan jika nilai sig $\geq$ 0,05 maka data berdistribudi normal, sedangkan jika nilai sig $\leq 0,05$ maka data tidak berdistribusi normal. Berdasar hasil uji normalitas data diketahui bahwa seluruh data memiliki nilai signifikansi $(0,071) \geq 0,05$ sehingga dapat disimpulkan seluruh data berdistribusi normal. Dengan data yang terdistribusi secara normal maka data-data ini dapat mewakili kondisi dari populasi dan dapat dilakukan pengujian dengan menggunakan statisik parametrik.

\section{b. Uji Homogenitas}

Uji homogenitas menggunakan model Levene Test for Equality of Variance. Dasar dari pengambilan keputusan ini adalah jika nilai signifikansi $\geq 0,05$ maka varian dinyatakan memiliki sifat yang sama atau homogen. Berdasarkan uji homogenitas yang dilakukan di ketahui, data pretest menunjukkan nilai signifikansi $0,142 \geq 0,05$. Sedangkan data posttest menunjukkan nilai signifikansi $0,064 \geq$ 0,05. Terlihat bahwa seluruh data memeliki nilai signifikansi $\geq 0,05$ sehingga disimpulkan seluruh data bersifat homogen.

\section{c. Uji hipotesis}

Uji hipotesis dalam penelitian ini dilakukan dengan menggunakan paired sample T-test karena hanya menggunakan satu kelompok penelitian saja dengan menguji nilai pretest dan posttest. Dengan dasar pengambilan keputusan apabila nilai signifikansi $\leq 0,05$ maka terdapat perbedaan yang signifikan antara pretest dan posttest. Berikut ini merupakan hasil dari uji hipotesis.

Diketahui nilai sig (2-tailed) menunjukkan nilai $0,000 \leq 0,05$ artinya ada pengaruh yang signifikan antara pretest dan posttest, sehingga dapat diartikan juga bahwa ada pengaruh yang signifikan Pendidikan Agama Kristen terhadap pemahaman tentang gambar diri.

\section{d. Uji Sumbangan Efektivitas}

Uji sumbangan efektivitas dalam penelitian ini menggunakan uji regresi, dimana diperoleh nilai $\mathrm{R}$ Square sebesar $31,3 \%$. Hasil ini menunjukkan bahwa pembelajaran pendidikan agama Kristen memberikan sumbangan efektif terhadap pemahaman mahasiswa tentang gambar diri sebanyak $31,3 \%$.

PAK efektif memberikan sumbangsih terhadap pemahaman tentang gambar diri yang alkitabiah karena dalam pembelajaran, dosen melakukan pengulangan materi dengan menggunakan beragam metode. Dosen dalam 
melaksanakan pembelajaran menggunakan pendekatan kelompok besar $(\mathrm{KB})$ kepada seluruh mahasiswa dengan metode ceramah, presentasi paper, diskusi, studi kasus etika sosial kontemporer dan retreat. Pendekatan kelompok kecil (KK) melalui melalui Kelompok Tumbuh Bersama Kontekstual (KTBK) atau Contextual Bible Group (CBG) dimana setiap kelompok belajar Alkitab terdiri dari seorang pemimpin dan 3-5 orang anggota ${ }^{27}$. Bahan yang digunakan yaitu Seri Bahan KTBK Teguh Di dalam Kristus (Surat I, II, II Yohanes). Bahan ini menolong mahasiswa untuk teguh di dalam iman kepada Kristus dan identitasnya sebagai anak-anak Allah. ${ }^{28}$ Seri Bahan KTBK Bertumbuh Ke Arah Kristus (Surat Kolose). Bahan ini mengarahkan anak-anak Allah untuk bertumbuh dalam segala hal ke arah Kristus dengan hikmat dan pengertian yang benar. ${ }^{29}$ Bahan KTBK Dewasa Di Dalam Kristus (Surat Efesus). Bahan ini menolong mahasiswa untuk menyadari statusnya di dalam Kristus dan bertumbuh menjadi dewasa di dalam Kristus. ${ }^{30}$ Sedangkan Pendekatan Pribadi (PP) melalui penugasan untuk membaca dan merenungkan bagian-bagian Alkitab yaitu Mazmur 139, surat 1 Yohanes 2:28-3:1-10 dan surat Kolose 1:1-4 dan surat Efesus 2:1-10. Perpaduan beragam pendekatan dan metode menghasilkan pemahaman yang lebih rangkum tentang gambar diri mahasiswa Kristen sebagai anak-anak Allah di dalam Kristus.

\footnotetext{
${ }^{27}$ T. Haryono dan T. Yuliati, Pemuridan Kontekstual, (Surakarta: Yayasan Gamaliel, 2018), 60.

${ }^{28}$ T. Haryono, Teguh Di Dalam Kristus, (Surakarta: Sekolah Tinggi Teologi Gamaliel, 2018), 12-13.

${ }^{29}$ T. Haryono, S. Kawangmani, Seri KTBK Bertumbuh Ke Arah Kristus (Surakarta: Sekolah Tinggi Teologi Gamaliel, 2016), 8-9.

${ }^{30}$ T. Haryono, Soleman Kawangmani, Santosa N. Djati, Seri KTBK Dewasa Dalam Kristus (Surakarta: Sekolah Tinggi Teologi Gamaliel, 2008), 4-5.
}

\section{KESIMPULAN DAN SARAN}

Kesimpulan penelitian yaitu pembelajaran agama Kristen melalui Mata Kuliah PAK di Perguruan Tinggi umum efektif meningkatkan pemahaman tentang gambar diri mahasiswa Kristen sebagai anak-anak Allah di dalam Kristus sebesar $31,3 \%$. Efektivitas sumbangsih PAK terhadap pemahaman gambar diri mahasiswa Kristen ini terkait erat dengan penyampaian materi secara berulang-ulang dan penerapan beragam pendekatan dan metode pembelajaran.

Saran bagi semua dosen PAK di Perguruan Tinggi umum agar mempersiapkan materi ajar, pendekatan dan metode belajar yang beragam agar PAK menjadi berkat dalam membentuk mahasiswa Kristen sebagai anak-anak Allah dan calon pemimpin yang sungguhsungguh hidup sesuai gambar dirinya yaitu anak-anak Allah di dalam Kristus.

\section{DAFTAR PUSTAKA}

Anderson, Neil T., Siapa Anda Sesungguhnya?, Bandung: Lembaga Literatur Baptis, 2004

Berkhof, Louis, Teologia Sistematika, Jilid 2, Jakarta: LRII, 1994

Enns, Paul, The Moody Handbook of Theology, Chicago: Moody Press, 1989

Evans, Tony, Sungguh-sungguh Diselamatkan, Batam: Gospel Press, 2005

Haryono, T, Saved by Faith, Surakarta: Yayasan Gamaliel, 2015.

Haryono, T., Ginting, R., Kawangmani, Soleman, Yuliati, Nurwindayani, Efi, Harjanto, Hery, Sanger, Jimmy K., Pendidikan Agama Kristen, Surakarta: LPPMP UNS, 2016

Haryono T, Yuliati T, Pemuridan Kontekstual, Surakarta: Yayasan Gamaliel, 2018 
Haryono, T, Teguh Di Dalam Kristus, Surakarta: Sekolah Tinggi Teologi Gamaliel, 2018

Haryono, T, Kawangmani, S., Seri KTBK Bertumbuh Ke Arah Kristus, Surakarta: Sekolah Tinggi Teologi Gamaliel, 2016

Haryono, T, Kawangmani, S, Djati, N. Santosa, Seri KTBK Dewasa Dalam Kristus, Surakarta: Sekolah Tinggi Teologi Gamaliel, 2008.

Lembaga Alkitab Indonesia, Alkitab, Jakarta: LAI, 2009

Lukmono, Irawan Budi, Pengembangan Pribadi, Karanganyar: GSJA Air Kehidupan, 2018

Kurniawan, Nicholas, "Membangun Konsep Diri Berdasarkan Firman Tuhan", Veritas $1 / 2$, Oktober, 2000

Kusrahmadi, Dwi, Sigit, "Sumbangan Pendidikan Agama Kristen Dalam Mewujudkan Watak Bangsa". http://staffnew.uny.ac.id/upload/13 1655977/ penelitian/ Jurnal+Pendidikan+ Agama+Kristen $+1+$ Nov.+2007.pdf

Merril, Eugene H., "A Theology of The Pentateukh" dalam A Biblical Theology of The Old Testament

Ryrie, Charles C., Pengantar Teologi Dasar, Jilid 1, Yogyakarta: Yayasan ANDI, 1993

Sabdono, Erastus, Gambar Diri, Jakarta: Rehobot Literature, 2017

Wolf, Herbert, An Introduction to The Old Testament Pentateuch, Chicago: Moody Press, 1991 